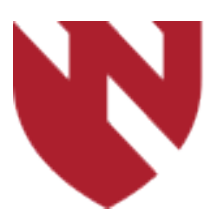

September 2020

\title{
PONV Prophylaxis Failure Disproportionately Affects Female Patients, Despite Intraoperative Computerized Decision Support Guidance
}

\author{
Karl A. Krieser \\ University of Michigan \\ John B. Riley III \\ University of Nebraska Medical Center \\ Jospeh E. Baus \\ University of Nebraska Medical Center \\ Julie T. Hoffman \\ University of Nebraska Medical Center \\ James N. Sullivan MD \\ University of Nebraska Medical Center
}

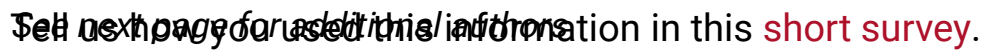

Follow this and additional works at: https://digitalcommons.unmc.edu/gmerj

Part of the Anesthesia and Analgesia Commons, and the Anesthesiology Commons

\section{Recommended Citation}

Krieser, K. A., Riley, J. B., Baus, J. E., Hoffman, J. T., Sullivan, J. N., , Lobato, R. L. PONV Prophylaxis Failure Disproportionately Affects Female Patients, Despite Intraoperative Computerized Decision Support Guidance. Graduate Medical Education Research Journal. 2020 Sep 29; 2(1).

https://digitalcommons.unmc.edu/gmerj/vol2/iss $1 / 6$ 


\title{
PONV Prophylaxis Failure Disproportionately Affects Female Patients, Despite Intraoperative Computerized Decision Support Guidance
}

\begin{abstract}
Objectives: To compare postoperative nausea and vomiting (PONV) prophylaxis treatment and outcomes based on patients' sex, using a retrospective cohort. The setting was the operating room and postanesthesia care unit of a tertiary care university medical center.

Patients: A total of 678 adult male and female patients with American Society of Anesthesiologist (ASA) scores of 1-4 underwent surgery with general anesthesia. All patients received preoperative PONV risk assessment. PONV prophylaxis was administered at the discretion of the anesthesia care team members with guidance from a computerized decision support system.

Measurements: Adequacy of prophylaxis was retrospectively determined based on individual patient risk factors and the observed treatment received, compared with guideline-based prophylaxis recommendations. Patient outcome was measured by diagnosis of PONV in recovery.

Results: Comparing patients who received fewer than the guideline-recommended number of prophylactic antiemetics by sex, $94.6 \%$ were female and $5.4 \%$ were males $(p<0.001)$. Patients who received fewer than guideline-recommended number of antiemetics had significantly higher rates of nausea or vomiting in the post-anesthesia care unit $(30.4 \%$ vs $17.5 \%, p<0.001)$.

Conclusion: This retrospective cohort study shows that female patients receiving general anesthesia are disproportionately affected by failure to adhere to PONV prevention guidelines.

\section{Creative Commons License} (c) (i) $(9)$
\end{abstract}

This work is licensed under a Creative Commons Attribution-Noncommercial-No Derivative Works 4.0 License.

\section{Cover Page Footnote}

Acknowledgements This research did not receive any specific grant from funding agencies in the public, commercial, or not-for-profit sectors.

\section{Authors}

Karl A. Krieser, John B. Riley III, Jospeh E. Baus, Julie T. Hoffman, James N. Sullivan MD, and Robert L. Lobato 


\section{PONV Prophylaxis Failure Disproportionately Affects Female Patients, Despite Intraoperative Computerized Decision Support Guidance}

Karl Krieser ${ }^{1}$, John Riley III², Joseph Baus², Julia Hoffman², James Sullivan², Robert Lobato ${ }^{2}$

${ }^{1}$ University of Michigan Hospitals, Department of Anesthesiology

${ }^{2}$ University of Nebraska Medical Center, Department of Anesthesiology

\begin{abstract}
Objectives: To compare postoperative nausea and vomiting (PONV) prophylaxis treatment and outcomes based on patients' sex, using a retrospective cohort. The setting was the operating room and post-anesthesia care unit of a tertiary care university medical center.
\end{abstract}

Patients: A total of 678 adult male and female patients with American Society of Anesthesiologist (ASA) scores of 1-4 underwent surgery with general anesthesia. All patients received preoperative PONV risk assessment. PONV prophylaxis was administered at the discretion of the anesthesia care team members with guidance from a computerized decision support system.

Measurements: Adequacy of prophylaxis was retrospectively determined based on individual patient risk factors and the observed treatment received, compared with guideline-based prophylaxis recommendations. Patient outcome was measured by diagnosis of PONV in recovery.

Results: Comparing patients who received fewer than the guideline-recommended number of prophylactic antiemetics by sex, $94.6 \%$ were female and $5.4 \%$ were males $(\mathrm{p}<0.001)$. Patients who received fewer than guideline-recommended number of antiemetics had significantly higher rates of nausea or vomiting in the post-anesthesia care unit $(30.4 \%$ vs $17.5 \%, \mathrm{p}<0.001)$.

Conclusion: This retrospective cohort study shows that female patients receiving general anesthesia are disproportionately affected by failure to adhere to PONV prevention guidelines.

\section{Introduction}

Postoperative nausea and vomiting (PONV) is a common complication associated with general anesthesia. Incidence of PONV is approximately $30 \%$ in the general population and up to $80 \%$ in high-risk individuals. ${ }^{1,2}$ Postoperative vomiting increases risk of aspiration, pneumothorax, esophageal rupture and wound dehiscence. ${ }^{3,4}$ PONV may also lead to prolonged time in post-anesthesia care units (PACU), as well as unplanned admissions following ambulatory surgery. From a patient satisfaction point of view, nausea and vomiting are reported as among the least desired outcomes following surgery. ${ }^{8}$

Risk scores:Koivuranta et al. created an original PONV risk assessment instrument based on five factors; one of those being female sex. ${ }^{2}$ Apfel et al. introduced a simplified risk score using four risk factors to better predict a patients' risk of PONV: ${ }^{1}$ history of prior PONV or motion sickness, female sex, nonsmoker status, and anticipated postoperative opioid administration. In pediatrics, the Postoperative vomiting in Children (POVOC) score is most commonly used and does not take into consideration the sex of the patient, as sex does not change PONV risk in prepubescent children. ${ }^{9}$

Female Sex as a Risk Factor: Female sex is the strongest clinical predictor of PONV, and female patients are 2-3 times more likely to experience PONV compared to males. ${ }^{10}$ Females also experience reduced beneficial effects from pharmacological prophylaxis. ${ }^{11}$ The exact mechanisms responsible for the increased incidence of PONV in females are unknown. Studies have suggested that PONV risk in females is influenced by menstrual phase, with the highest risk occurring during the follicular phase and lowest risk during the luteal phase. ${ }^{12,13,14}$ However, these results are inconsistent, with poor reproducibility between studies, casting uncertainty regarding the influence of sex hormones on predisposition towards nausea and vomiting. ${ }^{15}$

Utilization of CDSS: Despite the creation of a simplified risk score and consensus guidelines on PONV prevention and treatment, pharmacologic prophylaxis rates are reported to be as low as $37 \%$ in moderate and high risk patients. ${ }^{1,16,17}$ To improve guideline adherence among clinicians, information technology solutions have been proposed, including electronic clinical decision support systems (CDSS). CDSS are automated tools that filter available patient data within the electronic medical record (EMR) to provide timely reminders and suggested treatments during episodes of care. At our institution, a CDSS is used to automatically calculate surgical patients' Apfel risk score and prompt the anesthesia provider to administer PONV prophylaxis. Previous studies have reported that implementation of CDSS for PONV prevention has increased guideline adherence and lowered PONV incidence. ${ }^{18,19}$ Other successful CDSS integrations reported in anesthesia literature include intraoperative glucose monitoring, intraoperative blood pressure control and antibiotic administration less than 60 minutes prior to skin incision..$^{20,21}$

Academic Practice: While decision support tools can provide evidence-based prompts and treatment suggestions, patient care is ultimately under the control and clinical judgement of individual providers. In academic practices, the anesthesia care team is comprised of a variety of clinicians (e.g., physician anesthesiologists, nurse anesthetists and anesthesiology residents). This diversity of individuals, with different experience and training, can result in markedly different clinical care decisions. With respect to the management of PONV, personal preference and individual viewpoints of the clinician can affect adherence with published recommendations and guidelines. Despite published consensus recommendations and implementation of CDSS, we hypothesize that female patients are not receiving the same level of prophylaxis as males.

\section{Methods}

This retrospective study was approved by the University of Nebraska Medical Center (UNMC) Institutional Review Board (IRB). Informed consent for this retrospective study of existing EMR data was waived by the UNMC IRB. Records were obtained from consecutive, elective surgical procedures performed under general anesthesia on adult patients between January 2, 2017 and March 31,2017 . Patients with incomplete or missing clinical data were excluded from analysis. UNMC is a tertiary-care teaching hospital that utilizes an anesthesia care team model. Care teams are led by physician anesthesiologists who oversee the care of patients by certified registered nurse anesthetists (CRNA) or anesthesiology residents. Preoperative screening, anesthetic technique planning, intraoperative management and postanesthesia care were at the discretion of the care team anesthesiologists, CRNAs and anesthesiology residents.

Preoperative and post-anesthesia data were prospectively entered into the electronic medical record EPIC Systems software (Epic, Verona, WI) as a routine part of patient care. Intraoperative data were collected with 
EPIC Anesthesia Information Management System (AIMS) in all facilities and operating rooms. Each patient received a preoperative assessment of their PONV risk within the EPIC EMR. The PONV assessment questions were retrospectively used to determine the prophylaxis level for each patient in the study. Prophylaxis levels were determined using the 2014 consensus guidelines for PONV and are based on patients' Apfel risk score. ${ }^{16}$ The following intraoperative prophylaxis treatment categories were then constructed (Table 1).

Intraoperative decision support was used to remind the anesthesia care team members of the patients' risk and indication of PONV prophylaxis. The clinical decision support system utilized the data points acquired during the preoperative PONV risk assessment to determine if a patient was at risk. Our CDSS notifies providers of at-risk patients and suggests intraoperative administration of antiemetics for PONV prophylaxis.

For the purposes of this study, an episode of PONV was defined as nausea or vomiting in the post-anesthesia care unit (PACU) requiring the administration of a rescue antiemetic medication. Antiemetics available to be used for either prophylaxis or rescue included ondansetron, diphenhydramine, lorazepam, prochlorperazine, promethazine, scopolamine, haloperidol, metoclopramide and dexamethasone. Choice of agent was at the discretion of the treating care team members.

Data retrieved from EPIC were analyzed using R statistical computing environment ( $\mathrm{R}$ Core Team, 2019). Results are presented as number (percent) or mean (standard deviation) where appropriate. Chi-squared tests were used to compare categorical variables. P-values less than 0.05 were deemed statistically significant.

\section{Results}

A total of 747 adult patients were eligible for inclusion in the retrospective cohort. Of those, 69 patients were excluded for incomplete or missing clinical data, producing a final cohort size of 678 participants. Clinical demographics and PONV risk factors are presented in Table 2.

Treatment and Outcomes: The total incidence of PONV for all patients in the cohort was $21.1 \%$. Prophylaxis rates varied significantly across risk categories, with $93.2 \%$ of the low risk group receiving more pharmacologic prophylaxis than recommended by guidelines. Conversely, $85.7 \%$ of patients in the high risk group

Table 1.

PONV risk category based on number of risk factors and intraoperative antiemetics.

\begin{tabular}{cccc} 
& \multicolumn{3}{c}{ PONV Risk Category } \\
\cline { 2 - 4 } $\begin{array}{c}\text { Intraoperative } \\
\text { Antiemetics } \\
\text { Administered }\end{array}$ & $\begin{array}{c}\text { Low } \\
\text { (0 Risk Factors) }\end{array}$ & $\begin{array}{c}\text { Moderate } \\
\text { (1 or 2 Risk Factors) }\end{array}$ & $\begin{array}{c}\text { High } \\
\text { (3+ Risk Factors) }\end{array}$ \\
\hline None & Adequate & Under & Under \\
\hline 1 or 2 & Over & Adequate & Under \\
\hline $3+$ & Over & Over & Adequate
\end{tabular}

received fewer agents than consensus guidelines suggest $(p<0.001)$. Patients in the moderate risk group received the guideline-recommended number of antiemetic prophylaxis medications in $87.3 \%$ of cases (Table 3).

Similarly, PONV rates varied significantly across prophylaxis categories. Among patients who were considered inadequate prophylaxis, $30.4 \%$ required treatment for PONV while in the recovery area (Table 4). In contrast, patients who received adequate prophylaxis or excessive prophylaxis were treated for PONV in $17.5 \%$ and $13.5 \%$ of cases, respectively ( $p$ $<0.001)$.

Treatment and Outcomes Based on Sex: Female patients received significantly different PONV prophylaxis regimens and experienced PONV significantly more often than male patients (Table 5). Female patients were under prophylaxed at significantly higher rates than male patients (58.4\% vs. $4.5 \%$, respectively, $\mathrm{p}<0.001)$. Of patients receiving fewer prophylaxis medications than guidelines recommend, $94.6 \%$ were female (Table 6 and Figure 1). Female patients also required symptomatic treatment for PONV in $28.0 \%$ of cases, a significantly higher rate than the $11.8 \%$ observed among male patients $(\mathrm{p}<0.001)$. Of note, baseline PONV risk factors varied significantly between male and female patients. Females had a higher rate of prior PONV or motion sickness history, $21.6 \%$, compared to $4.5 \%$ among male patients $(\mathrm{P}<0.001)$. Female patients also received postoperative opioids significantly more frequently than did male patients $(73.5 \%$ vs. $64.4 \%$, respectively, $\mathrm{p}=0.01)$. There was no significant difference in smoking status between female and male patients. Recovery times in PACU were similar between males and females.

\section{Discussion}

In this retrospective cohort study, we report that PONV prophylaxis failure disproportionately affects female patients undergoing surgery requiring general
Table 2.

Clinical demographics and PONV risk factors.

\begin{tabular}{|c|c|}
\hline & Overall $(\mathrm{N}=678)$ \\
\hline \multicolumn{2}{|l|}{ Age } \\
\hline Mean (SD) & $54.47(16.25)$ \\
\hline \multicolumn{2}{|l|}{ BMI } \\
\hline Mean (SD) & $31.17(8.51)$ \\
\hline \multicolumn{2}{|l|}{ ASA } \\
\hline 1 & $51(7.5 \%)$ \\
\hline 2 & $218(32.2 \%)$ \\
\hline 3 & $373(55.0 \%)$ \\
\hline 4 & $36(5.3 \%)$ \\
\hline \multicolumn{2}{|l|}{ Sex } \\
\hline Female & $389(57.4 \%)$ \\
\hline Male & $289(42.6 \%)$ \\
\hline \multicolumn{2}{|l|}{ Smoking Status } \\
\hline Current Smoker & $119(17.6 \%)$ \\
\hline Nonsmoker & $559(82.4 \%)$ \\
\hline \multicolumn{2}{|c|}{ Postoperative Opioids } \\
\hline No & $206(30.4 \%)$ \\
\hline Yes & $472(69.6 \%)$ \\
\hline \multicolumn{2}{|l|}{ History of PONV } \\
\hline No & $581(85.7 \%)$ \\
\hline Yes & $97(14.3 \%)$ \\
\hline \multicolumn{2}{|l|}{ Apfel Risk Score } \\
\hline 0 & $20(2.9 \%)$ \\
\hline 1 & $127(18.7 \%)$ \\
\hline 2 & $259(38.2 \%)$ \\
\hline 3 & $217(32.0 \%)$ \\
\hline 4 & $55(8.1 \%)$ \\
\hline \multicolumn{2}{|l|}{ Risk Category } \\
\hline Low (Apfel 0-1) & $147(21.7 \%)$ \\
\hline Moderate (Apfel 2) & $259(38.2 \%)$ \\
\hline High (Apfel 3-4) & $272(40.1 \%)$ \\
\hline
\end{tabular}

anesthesia. As a group, the majority of female patients, $58.4 \%$, were administered fewer than the guideline-recommended number antiemetics to prevent PONV. In contrast, only $4.5 \%$ of male patients received fewer than the recommended number of prophylactic antiemetics. Female patients were also significantly over-represented in 
the under-prophylaxed group, making up $94.6 \%$ of the patient total. In addition, the corresponding rates of nausea or vomiting requiring treatment among female patients was more than twice that observed among male patients $(28.0 \%$ vs. $11.8 \%)$. The overall observed rate of PONV within the cohort was $21.1 \%$, slightly lower than that reported in the general population. ${ }^{16,22}$

Female patients' predisposition towards PONV has been well established, as female sex is the strongest reported risk factor for the development of postoperative nausea and vomiting. ${ }^{10}$ In this cohort, female patients also had higher rates of two other PONV risk factors, namely prior history of PONV/ motion sickness and postoperative opioid administration. Our study also highlights inconsistent PONV prophylaxis guideline compliance at our institution, specifically in the high-risk patients, who were under prophylaxis in $87.5 \%$ of cases. This failure to adhere to PONV prevention guidelines is particularly surprising given the presence of intraoperative CDSS tools specifically designed to address PONV risk factors during intraoperative patient care.

Investigating the effectiveness of CDSS for PONV prophylaxis compliance was outside the scope of this study. A report by Kooij et al., however, described increased adherence to PONV guidelines following CDSS implementation, specifically in high risk patients. ${ }^{18}$ In their study, CDSS was limited to the preoperative screening clinic and was not in the setting of the operating room environment. Gabel et al. extended the use of clinical decision support technology by incorporating preoperative decision support, intraoperative checklists and personalized email reports to achieve of reduction in PONV incidence. ${ }^{23}$ Our investigation suggests that an intraoperative CDSS alone may be insufficient to affect improvements in adherence with PONV consensus guidelines.

Our study has several limitations. The clinical data gathered to calculate risk scores were dependent on the accuracy of preoperative assessments. Information bias, in which patients selectively or inconsistently recall details, could cause patients to inadvertently misrepresent their actual PONV risk. Inaccurate PONV risk assessments affect not only individual clinician's treatment decisions but also the CDSS results and prompts.

Because this was an observational study, not an interventional trial, there was no required modification in clinical care in response to the calculated Apfel PONV risk score
Table 3.

Prophylaxis administration by risk category.

\begin{tabular}{lcccc} 
& $\begin{array}{c}\text { Low } \\
(\mathrm{N}=147)\end{array}$ & $\begin{array}{c}\text { Moderate } \\
(\mathrm{N}=259)\end{array}$ & $\begin{array}{c}\text { High } \\
(\mathrm{N}=272)\end{array}$ & p value \\
\hline Risk Category & & & & $<\mathbf{0 0 1}$ \\
Under prophylaxis & $0(0 \%)$ & $7(2.7 \%)$ & $233(85.7 \%)$ & \\
Adequate prophylaxis & $10(6.8 \%)$ & $226(87.3 \%)$ & $39(14.3 \%)$ & \\
Over prophylaxis & $137(93.2 \%)$ & $26(10.0 \%)$ & $0(0 \%)$ &
\end{tabular}

Table 4.

Rates of PONV by prophylaxis category.

\begin{tabular}{lcccc} 
& $\begin{array}{c}\text { Under Prophylaxis } \\
(\mathrm{N}=240)\end{array}$ & $\begin{array}{c}\text { Adequate Prophylaxis } \\
(\mathrm{N}=275)\end{array}$ & $\begin{array}{c}\text { Over Prophylaxis } \\
(\mathrm{N}=163)\end{array}$ & p value \\
\hline PONV in Recovery & & & & $<\mathbf{0 . 0 0 1}$ \\
No PONV & $167(69.6 \%)$ & $227(82.5 \%)$ & $141(86.5 \%)$ & \\
PONV & $73(30.4 \%)$ & $48(17.5 \%)$ & $22(13.5 \%)$
\end{tabular}

Table 5.

Comparison of risk factors, PONV prophylaxis rates and PONV rates by sex.

\begin{tabular}{|c|c|c|c|}
\hline & $\begin{array}{l}\text { Female } \\
(\mathrm{N}=389)\end{array}$ & $\begin{array}{c}\text { Male } \\
\mathrm{N}=289)\end{array}$ & $p$ value \\
\hline Smoking Status & & & 0.504 \\
\hline Current Smoker & $65(16.7 \%)$ & $54(18.7 \%)$ & \\
\hline Nonsmoker & $324(83.3 \%)$ & $235(81.3 \%)$ & \\
\hline Postoperative Opioids & & & 0.010 \\
\hline No & $103(26.5 \%)$ & $103(35.6 \%)$ & \\
\hline Yes & $286(73.5 \%)$ & $186(64.4 \%)$ & \\
\hline History of PONV & & & $<0.001$ \\
\hline No & $305(78.4 \%)$ & $276(95.5 \%)$ & \\
\hline Yes & $84(21.6 \%)$ & $13(4.5 \%)$ & \\
\hline Level of prophylaxis & & & $<0.001$ \\
\hline Under prophylaxis & $227(58.4 \%)$ & $13(4.5 \%)$ & \\
\hline Adequate prophylaxis & $132(33.9 \%)$ & $143(49.5 \%)$ & \\
\hline Over prophylaxis & $30(7.7 \%)$ & $133(46.0 \%)$ & \\
\hline PONV in recovery & & & $<0.001$ \\
\hline No PONV & $280(72.0 \%)$ & $255(88.2 \%)$ & \\
\hline PONV & $109(28.0 \%)$ & $34(11.8 \%)$ & \\
\hline
\end{tabular}

Table 6.

Rates of PONV by prophylaxis category.

\begin{tabular}{lcccc} 
& $\begin{array}{c}\text { Under Prophylaxis } \\
(\mathrm{N}=240)\end{array}$ & $\begin{array}{c}\text { Adequate Prophylaxis } \\
(\mathrm{N}=275)\end{array}$ & $\begin{array}{c}\text { Over Prophylaxis } \\
(\mathrm{N}=163)\end{array}$ & $\mathrm{p}$ value \\
\hline Sex & & & \\
Female & $227(94.6 \%)$ & $132(48.0 \%)$ & $30(18.4 \%)$ & \\
Male & $13(5.4 \%)$ & $143(52.0 \%)$ & $133(81.6 \%)$
\end{tabular}




\section{Prophylaxis Categories by Sex}

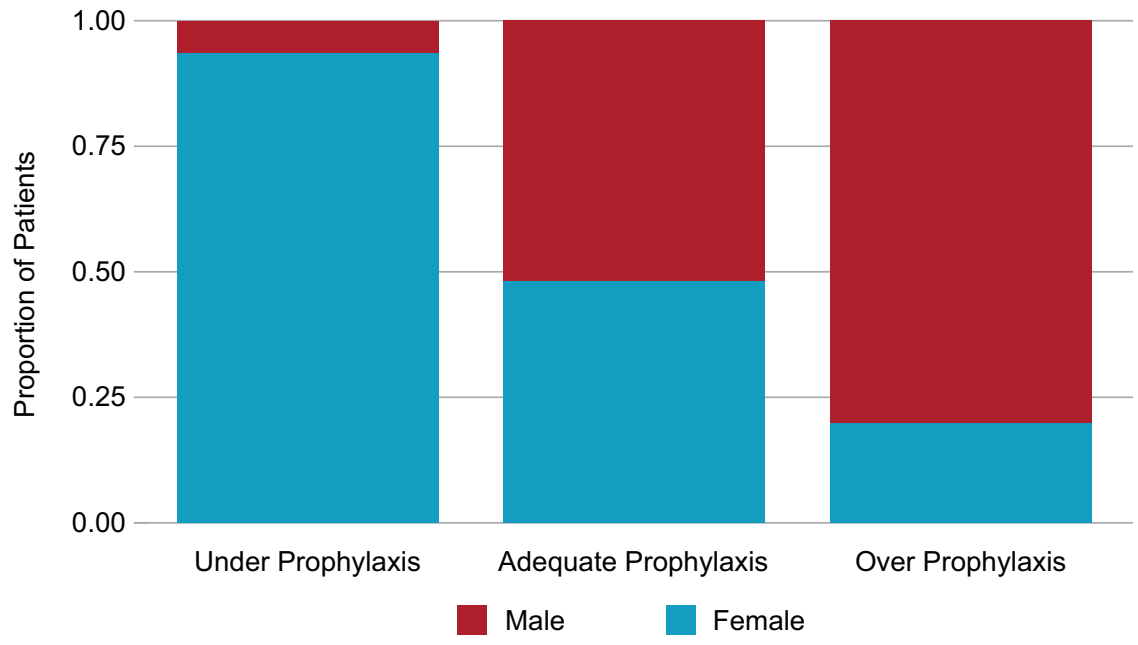

Figure 1. Proportion of patients based on sex for under, adequate and over prophylaxis $(p<0.001)$.

or mandatory reaction to the prompts and reminders provided by the CDSS.

We report that female patients are disproportionately affected by failure to adhere to PONV prevention and treatment guidelines. Furthermore, this disparity was particularly glaring in an environment where CDSS technology was employed to identify patients with multiple PONV risk factors for immediate treatment by an anesthesia care team. Future investigations will be needed to elucidate underlying causes for deviation from PONV prophylaxis guidelines by individual practitioners and for the systematic undertreatment of PONV in female patients.

https://doi.org/10.32873/unmc.dc.gmerj.2.1.091

\section{References}

1 Apfel CC, Laara E, Koivuranta M, Greim CA, Roewer N. A simplified risk score for predicting postoperative nausea and vomiting: conclusions from cross-validations between two centers. Anesthesiology. 1999;91:693-700. https://doi.org/10.1097/00000542199909000-00022.

2 Koivuranta M, Laara E, Snare L, Alahuhta S. A survey of postoperative nausea and vomiting. Anaesthesia. 1997;52:443-9. https://doi.org/10.1111/j.13652044.1997.117-az0113.x.

3 Schumann R, Polaner DM. Massive subcutaneous emphysema and sudden airway compromise after postoperative vomiting. Anesth Analg 1999;89:796-7. https://doi.org/10.1097/00000539-199909000-00050.

4 Col C, Soran A, Col M. Can postoperative abdominal wound dehiscence be predicted? Tokai J Exp Clin Med. 1998;23:123-7.

5 Ganter MT, Blumenthal S, Dubendorfer S, Brunnschweiler S, Hofer T, Klaghofer R, et al. The length of stay in the post-anaesthesia care unit correlates with pain intensity, nausea and vomiting on arrival. Perioper Med. (London, England) 2014;3:10. https://doi.org/10.1186/s13741-014-0010-8.
6 Gabriel RA, Waterman RS, Kim J, Ohno-Machado L. A Predictive Model for Extended Postanesthesia Care Unit Length of Stay in Outpatient Surgeries. Anesth Analg. 2017;124:1529-36. https://doi.org/10.1213/ ANE.0000000000001827.

7 Gold BS, Kitz DS, Lecky JH, Neuhaus JM. Unanticipated admission to the hospital following ambulatory surgery. JAMA. 1989;262:3008-10.

8 Macario A, Weinger M, Carney S, Kim A. Which Clinical Anesthesia Outcomes Are Important to Avoid? The Perspective of Patients. Anesth Analg. 1999;89.

9 Eberhart LHJ, Geldner G, Kranke P, Morin AM, Schauffelen A, Treiber H, et al. The development and validation of a risk score to predict the probability of postoperative vomiting in pediatric patients. Anesth Analg. 2004;99:1630-7, table of contents. https://doi. org/10.1213/01.ANE.0000135639.57715.6C.

10 Apfel CC, Heidrich FM, Jukar-Rao S, Jalota L, Hornuss C, Whelan RP, et al. Evidence-based analysis of risk factors for postoperative nausea and vomiting $\dagger$ BJA Br J Anaesth. 2012;109:742-53. https://doi. org/10.1093/bja/aes276.

11 Brettner F, Janitza S, Prüll K, Weninger E, Mansmann U, Küchenhoff H, et al. Gender-Specific Differences in Low-Dose Haloperidol Response for Prevention of Postoperative Nausea and Vomiting: A RegisterBased Cohort Study. PLoS One. 2016;11:e0146746e0146746. https://doi.org/10.1371/journal. pone. 0146746

12 Simurina T, Mraovic B, Skitarelic N, Andabaka T, Sonicki Z. Influence of the menstrual cycle on the incidence of nausea and vomiting after laparoscopic gynecological surgery: a pilot study. J Clin Anesth. 2012;24:185-92. https://doi.org/10.1016/j. jclinane.2011.07.011.

13 Beattie WS, Lindblad T, Buckley DN, Forrest JB. The incidence of postoperative nausea and vomiting in women undergoing laparoscopy is influenced by the day of menstrual cycle. Can J Anaesth. 1991;38:298302. https://doi.org/10.1007/BF03007618.

14 Beattie WS, Lindblad T, Buckley DN, Forrest JB. Menstruation increases the risk of nausea and vomiting after laparoscopy. A prospective randomized study. Anesthesiology. 1993;78:272-6. https://doi. org/10.1097/00000542-199302000-00010.

15 ratz I, Allen E, Afshar M, Joslyn AF, Buxbaum J, Prilliman B. The effects of the menstrual cycle on the incidence of emesis and efficacy of ondansetron. Anesth Analg. 1996;83:565-9. https://doi. org/10.1097/00000539-199609000-00022.
16 Gan TJ, Diemunsch P, Habib AS, Kovac A, Kranke $\mathrm{P}$, Meyer TA, et al. Consensus guidelines for the management of postoperative nausea and vomiting. Anesth Analg. 2014;118:85-113. https://doi. org/10.1213/ANE.0000000000000002.

17 Kumar A, Brampton W, Watson S, Reid VL, Neilly D Postoperative nausea and vomiting: simple risk scoring does work. Eur J Anaesthesiol. 2012;29:57-60. https:// doi.org/10.1097/EJA.0b013e32834a3d81.

18 Kooij FO, Klok T, Hollmann MW, Kal JE. Decision support increases guideline adherence for prescribing postoperative nausea and vomiting prophylaxis. Anesth Analg. 2008;106:893-8, table of contents. https://doi. org/10.1213/ane.0b013e31816194fb.

19 Kooij FO, Vos N, Siebenga P, Klok T, Hollmann MW, $\mathrm{Kal}$ JE. Automated reminders decrease postoperative nausea and vomiting incidence in a general surgical population. Br J Anaesth. 2012;108:961-5. https://doi. org/10.1093/bja/aes024.

20 Nair BG, Grunzweig K, Peterson GN, Horibe M, Neradilek MB, Newman S-F, et al. Intraoperative blood glucose management: impact of a real-time decision support system on adherence to institutiona protocol. J Clin Monit Comput. 2016;30:301-12. https://doi.org/10.1007/s10877-015-9718-3.

21 Nair BG, Horibe M, Newman S-F, Wu W-Y, Peterson $\mathrm{GN}$, Schwid HA. Anesthesia information management system-based near real-time decision support to manage intraoperative hypotension and hypertension. Anesth Analg. 2014;118:206-14. https://doi.org/10.1213/ANE.0000000000000027.

22 Kazemi-Kjellberg F, Henzi I, Tramer MR. Treatment of established postoperative nausea and vomiting: a quantitative systematic review. BMC Anesthesiol. 2001;1:2. https://doi.org/10.1186/1471-2253-1-2.

23 Gabel E, Shin J, Hofer I, Grogan T, Ziv K, Hong J, et al. Digital Quality Improvement Approach Reduces the Need for Rescue Antiemetics in HighRisk Patients: A Comparative Effectiveness Study Using Interrupted Time Series and Propensity Score Matching Analysis. Anesth Analg. 2019;128. 